\title{
Connaissances endogènes et contraintes biotiques de production des haricots cultivés du genre Phaseolus au Centre et Sud Bénin (Afrique de l'Ouest).
}

\author{
Houssou Wilfried MILOGNON ${ }^{1,2 *}$; Antoine Abel MISSIHOUN 1,2 ; Relique Ignace AGBO ${ }^{1,2}$ Achille \\ Ephrem ASSOGBADJO ${ }^{3}$ et Clément AGBANGLA ${ }^{1,2}$. \\ 'Laboratoire de Génétique Moléculaire et d'Analyse des Génomes, Faculté des Sciences et Techniques, Université \\ d'Abomey-Calavi, 01 BP 526, Cotonou, Bénin. \\ 2Laboratoire de Génétique et des Biotechnologies, Faculté des Sciences et Techniques, Université d'Abomey-Calavi, \\ 01BP 526, Cotonou, Bénin. \\ ¿Laboratoire d'Ecologie Appliquée, Faculté des Sciences Agronomiques, Université d'Abomey-Calavi, 05 BP 1752, \\ Cotonou, Bénin. \\ *Auteur correspondant : frignhone@gmail.com ; Tél : +229-94-25-81-15 / 67-77-19-30.
}

Original submitted in on $14^{\text {th }}$ October 2019. Published online at www.m.elewa.org/journals/ on $31^{\text {st }}$ January 2020 https://doi.org/10.35759/JABs.145.9

\section{RÉSUMÉ}

Objectif: L'objectif de la présente étude est d'évaluer les connaissances endogènes et les contraintes biotiques liées à la production des haricots, et de recenser les traits locaux de dénominations qui caractérisent les espèces du genre Phaseolus au Centre et Sud Bénin.

Méthodologie et résultats : Treize (13) villages du Centre et Sud Bénin ont été prospectés en Mai 2017 et Janvier 2019 selon les outils et technique d'une approche de recherche participative basée sur des discussions libres, des entretiens de groupes et/ou individuels et des visites de champs. Les résultats ont montré une variation en ce qui concerne les critères de dénomination des espèces qui sont principalement basés sur le type de plante, la couleur, la dimension et les usages particuliers des graines. D'après les producteurs, les maladies qui menacent les haricots sont des viroses, des maladies d'origine bactérienne ou fongique avec plusieurs espèces de ravageurs des feuilles, des gousses et des graines. Cinq (5) catégories d'usages par espèce de haricot ont été recensées parmi lesquelles l'usage alimentaire est le plus important avec une large gamme d'utilisation de l'espèce Phaseolus vulgaris (CTUT $=0,98$ et $\left.\mathrm{CTU}_{P V}=0,68\right)$ alors que l'usage dans l'alimentation animale est plus faible $(C T U=0,08)$.

Conclusion et applications des résultats: Cette étude témoigne que les haricots sont d'une grande importance tant au plan nutritionnel, agronomique, médicinal, culturel/cultuel que spirituel pour les populations locales mais des contraintes pèsent sur la production de ces ressources au point où elles sont menacées de disparition. Des stratégies de valorisation et de conservation sont nécessaires pour préserver ces ressources génétiques.

Mots clés : Phaseolus spp., Valeur Consensuelle d'Usage (CTU), Ethnobotanique, Indice de diversité, Bénin. 
Endogenous knowledge and biotics constraints of production of cultivated beans of the Phaseolus genus in the central and Southern regions of Benin (West Africa).

\section{ABSTRACT}

Objective: The objective of this study is to assess endogenous knowledge and biotic constraints related to bean production, and to identify local denomination traits that characterize species of the genus Phaseolus in Central and South Benin.

Methodology and results: Thirteen (13) villages in Central and Southern Benin were prospected in May 2017 and January 2019 using the tools and technique of a participatory research approach based on free discussions, group and/or individual interviews and field visits. The results showed variation in species naming criteria that are primarily based on plant type, colour, size and specific uses of seeds. According to growers, the diseases that threaten beans are viruses, bacterial or fungal diseases with several species of leaf, pod and seed pests. Five (5) categories of uses per bean species were listed among which the food use is most significant with a broad range of use of the species Phaseolus vulgaris $\left(C T U_{t}=0,98\right.$ and $\left.\mathrm{CTU}_{\mathrm{Pv}}=0,68\right)$ whereas the use in the animal feeds is weaker $(\mathrm{CTU}=0,08)$.

Conclusion and applying the results: This study shows that beans are of great nutritional, agronomic, medicinal, cultural/cultural and spiritual importance to local populations, but there are constraints on the production of these resources to the point where they are threatened with extinction. Strategies for recovery and conservation are needed to preserve these genetic resources.

Keywords: Phaseolus spp. Consensual Value of Use (CTU), Ethnobotanic, Index of diversity, Benin.

\section{INTRODUCTION}

Les légumineuses à graines appartiennent à la famille des Fabacées qui sont classées dans l'ordre des Fabales. Les haricots du genre Phaseolus sont l'une d'entre elles. Du fait que les légumineuses peuvent utiliser directement l'azote minéral et atmosphérique, elles représentent une composante principale dans les systèmes agraires (Baudoin et al., 2002 ; Freytag \& Debouck, 2002 ; IRAD, 2013) et leur culture se répand dans le monde entier (CIAT, 1989). Source importante de vitamines et de protéines peu coûteuses dans le régime alimentaire de beaucoup de populations des pays tropicaux, les légumineuses à graines complètent fort heureusement les aliments riches en hydrates de carbone tels que les céréales, les tubercules et les racines (Ismet and Firkret, 2011; Roméro et al., 2013). De plus il est indiqué que la consommation des légumineuses permet un meilleur contrôle des maladies cardiovasculaires (Marilyn et al., 2011), le diabète (IRAD, 2013), l'obésité et le cancer colorectal (Taylor et al., 2012). Au Bénin, les haricots du genre phaseolus sont bien connus des populations locales et leur culture est réservée essentiellement aux petits fermiers qui les pratiquent souvent en association avec d'autres cultures pour l'autoconsommation (Akouègninou et al., 2006). Malheureusement ces cultures se caractérisent très souvent par des rendements faibles et instables surtout dans les pays en voie de développement (Baudoin, 2001) du fait des contraintes abiotiques telles que les effets des changements climatiques (sécheresse, hautes températures) (Bayuelo-Jiménez et al., 2003 ; Rainey et Griffiths, 2005) que biotiques dont les maladies fongiques, bactériennes et virales (Mahuku et al., 2002 ; Caixeta et al., 2003), mais aussi de l'absence de variétés tolérantes ou résistantes à ces contraintes. Ainsi, les ressources génétiques des espèces du genre Phaseolus deviennent de plus en plus rares ces dernières années malgré leurs considérations nutritionnelles, sanitaires et agronomiques. Clairement perçus comme aliments de base de nombreuses civilisations (Broughton et al., 2003), les bénéfices nutritionnels des haricots du genre Phaseolus sont sous-estimés dans le monde et ils sont considérés dans certaines cultures, comme la « nourriture du pauvre ». En conséquence, ils sont remplacées par de la protéine animale lorsque celle-ci est accessible (FAO, 2016) alors que les études 
scientifiques touchant les bienfaits nutritionnels, les difficultés de la gestion post-récolte et les diverses contraintes biotiques liées à la gestion des formes végétatives de ces ressources sont rares et presque inexistantes au Bénin. C'est dans ce contexte que la présente étude vise globalement à documenter les différents usages, les différentes maladies des formes végétatives et les difficultés de la gestion post-récolte des haricots du genre phaseolus cultivés par les

\section{MATÉRIEL ET MÉTHODES}

Présentation de la zone d'étude: L'étude ethnobotanique et la collecte des graines de différentes espèces des haricots se sont déroulées dans la zone subéquatoriale du Bénin qui jouit d'une pluviométrie variant entre 950 et $1400 \mathrm{~mm} / \mathrm{an}$ (MAEP, 2007). L'étude a été conduite dans sept communes du Sud et du Centre Bénin situées entre les parallèles $06^{\circ} 50^{\prime}$ et $08^{\circ} 06^{\prime}$ de latitude Nord puis entre $001^{\circ} 44^{\prime}$ et $002^{\circ} 12^{\prime}$ de longitude Est. II s'agit des communes de Glazoué et de Savalou dans le département des collines, de Djakotomey et de Toviklin dans le Couffo puis de populations locales du Bénin. De façon spécifique il s'est agi de : i) inventorier les maladies et les ravageurs des plantes au champ et des graines en post-récolte; ii) décrire les méthodes de lutte et techniques de stockage utilisées par les populations locales; et iii) recenser les catégories d'usages des différentes espèces de même que les critères locaux de dénominations des espèces de ce genre.

Agbangnizoun, Bohicon et Zogbodomey dans le Zou (Figure 1). Sur la base des données disponibles sur des cultures du même genre que les haricots tel que le niébé (Gbaguidi et al., 2015) et des connaissances de la culture des haricots, treize (13) villages de ces communes ont été choisis avec l'aide des Agences Territoriales de Développement Agricole (ATDA) et prospectés pendant les mois de Mai 2017 et de Janvier 2019. La plus grande partie de la zone d'étude est couverte par des sols ferrugineux et ferralitiques tropicaux

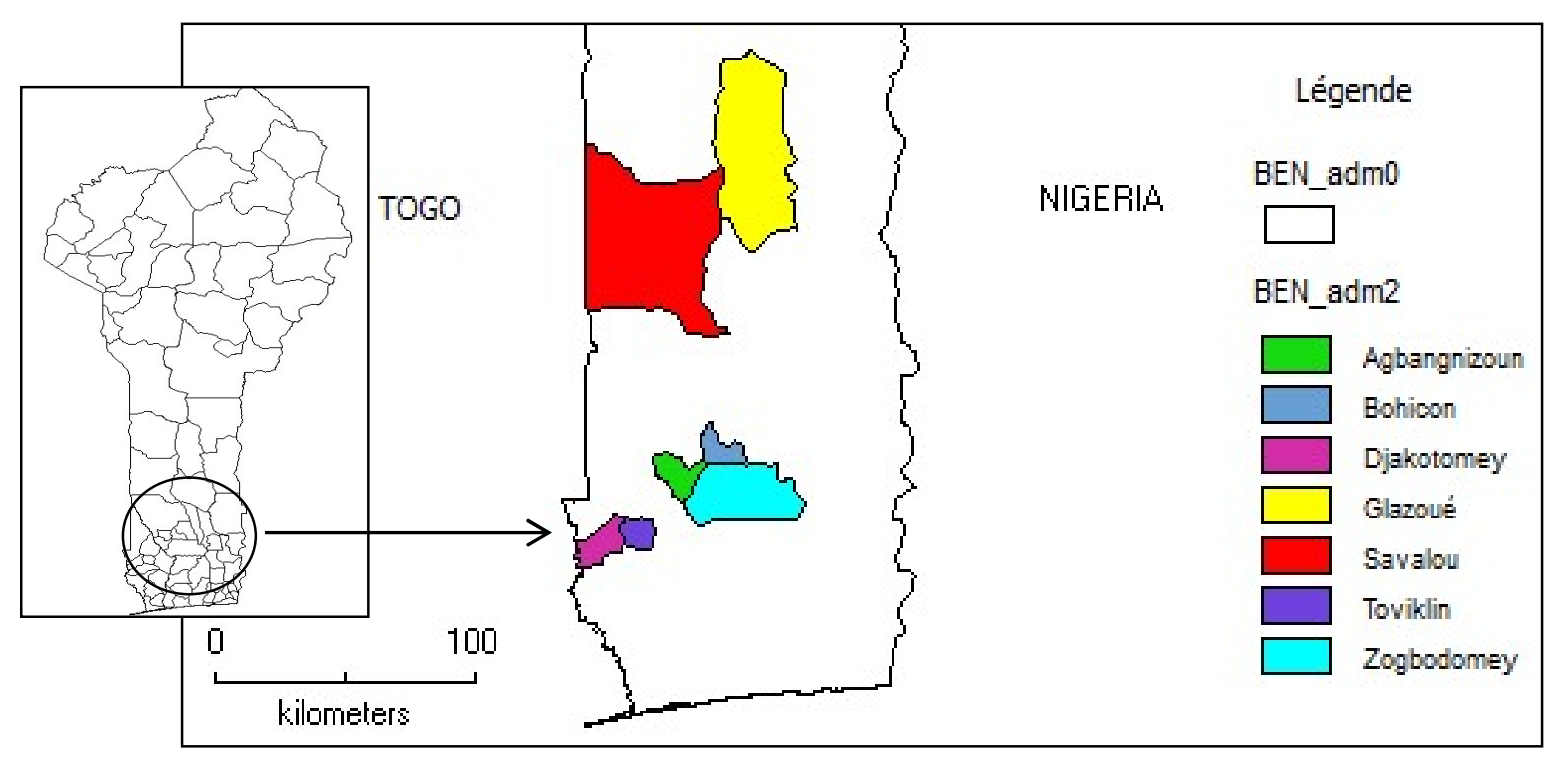

Figure 1 : Carte montrant la situation géographique des communes enquêtés. 
Tableau 1 : Situation géographique des communes et villages enquêtés.

\begin{tabular}{|c|c|c|c|c|}
\hline$N^{\circ}$ d'ordre & Communes & Villages enquêtés & Coordonnées GPS & Altitudes (m) \\
\hline \multirow[t]{2}{*}{1} & \multirow[b]{2}{*}{ Zogbodomey } & Hlagba-Zakpo & $\begin{array}{l}\mathrm{N}: 06^{\circ} 59,677^{\prime} \\
\mathrm{E}: 002^{\circ} 12,873^{\prime}\end{array}$ & 154 \\
\hline & & Zogbodomey & $\begin{array}{l}\mathrm{N}: 07^{\circ} 04,326^{\prime} \\
\mathrm{E}: 002^{\circ} 06,710^{\prime}\end{array}$ & 236 \\
\hline \multirow[t]{2}{*}{2} & \multirow[b]{2}{*}{ Agbangnizoun } & Adanhondjigon & $\begin{array}{l}\mathrm{N}: 07^{\circ} 05,937^{\prime} \\
\mathrm{E}: 002^{\circ} 01,113^{\prime}\end{array}$ & 489 \\
\hline & & Lissazounmè & $\begin{array}{l}N: 07^{\circ} 07,174^{\prime} \\
E: 002^{\circ} 00,246^{\prime}\end{array}$ & 574 \\
\hline \multirow[t]{2}{*}{3} & \multirow[b]{2}{*}{ Bohicon } & Lissèzoun/Houndon & $\begin{array}{l}\mathrm{N}: 07^{\circ} 11,869^{\prime} \\
\mathrm{E}: 02^{\circ} 03,461^{\prime}\end{array}$ & 633 \\
\hline & & Passagon/Djohounta & $\begin{array}{l}\mathrm{N}: 07^{\circ} 15,887^{\prime} \\
\mathrm{E}: 002^{\circ} 04,660^{\prime}\end{array}$ & 727 \\
\hline \multirow[t]{2}{*}{4} & \multirow[b]{2}{*}{ Savalou } & Monkpa & $\begin{array}{l}\mathrm{N}: 07^{\circ} 55,035^{\prime} \\
\mathrm{E}: 002^{\circ} 03,707^{\prime}\end{array}$ & 618 \\
\hline & & Lahotan & $\begin{array}{l}\mathrm{N}: 08^{\circ} 00,140^{\prime} \\
\mathrm{E}: 002^{\circ} 04,676^{\prime}\end{array}$ & 711 \\
\hline \multirow[t]{2}{*}{5} & \multirow[b]{2}{*}{ Glazoué } & Sowé & $\begin{array}{l}\mathrm{N}: 07^{\circ} 58,793^{\prime} \\
\mathrm{E}: 002^{\circ} 10,006^{\prime}\end{array}$ & 572 \\
\hline & & Ouèdèmè/ Liffodji & $\begin{array}{l}\mathrm{N}: 08^{\circ} 06,087^{\prime} \\
\mathrm{E}: 002^{\circ} 11,481^{\prime}\end{array}$ & 668 \\
\hline \multirow[t]{2}{*}{6} & \multirow[b]{2}{*}{ Djakotomey } & Houégamey/Damagahoué & $\begin{array}{l}\mathrm{N}: 06^{\circ} 52,755^{\prime} \\
\mathrm{E}: 001^{\circ} 45,303^{\prime}\end{array}$ & 317 \\
\hline & & Gohomey/Badahoué & $\begin{array}{l}\mathrm{N}: 06^{\circ} 50,383^{\prime} \\
\mathrm{E}: 001^{\circ} 44,731^{\prime}\end{array}$ & 225 \\
\hline 7 & Toviklin & Adjido/Dékandji & $\begin{array}{l}\mathrm{N}: 06^{\circ} 54,972^{\prime} \\
\mathrm{E}: 001^{\circ} 45,025^{\prime}\end{array}$ & 404 \\
\hline
\end{tabular}

Méthode de collecte des données: L'étude a été conduite dans treize (13) villages du Sud et du Centre Bénin selon les outils et techniques d'une approche de recherche participative basée sur les discussions libres, les entretiens de groupes et/ou individuels et des visites de champs suivant un guide d'entretien et d'un questionnaire (Adoukonou-Sagbadja et al., 2006; Missihoun et al., 2017). Ces villages ont été choisis suivant le critère d'accessibité avec l'aide des structures et services de vulgarisations agricoles telles les Agences Territoriales de Développement Agricole (ATDA) car les haricots ne sont pas produits partout à l'échelle nationale comme d'autres cultures telles que le maïs, le manioc, le soja, etc. Par conséquent, l'approche d'échantillonnage adoptée est constituée des personnes adultes ayant au moins 30 ans sans distinction de sexe afin de recueillir des informations fiables. Une enquête exploratoire a précédé l'enquête proprement dite et est réalisée sur un échantillon de 70 personnes par département administratif (Akouehou et al., 2014) prises aléatoirement. Ceci a permis de déterminer la probabilité $p$ des informateurs afin de fixer par calcul la taille de l'échantillon sur la base de la formule de Dagnelie (1998) établie selon l'algorithme :

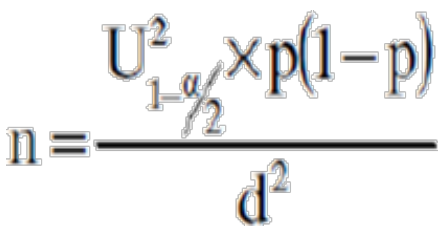

Où, $n$ : taille de l'échantillon considérée ;

$P$ : proportion d'informateurs qui utilisent l'espèce cible déterminée lors de la phase exploratoire dans le milieu $\left(P_{\text {Collines }}=0,94 ; P_{\text {Couffo }}=0,95 ; P_{\text {Zou }}=0,90\right)$;

U1- $\alpha / 2$ : valeur de la loi normale à la valeur de probabilité $1-\alpha / 2$ avec $\alpha=5 \%$ est de 1,96 ;

$\mathrm{d}$ : marge d'erreur de l'estimation fixée à une valeur de $8 \%$.

Cette pré-enquête a également permis de réorganiser le questionnaire adopté lors des enquêtes de terrain surtout par rapport aux critères de distinction des espèces du genre Phaseolus. Le tableau 3 présente la taille de l'échantillon considérée par département administratif et selon le sexe. Les informations recensées sont relatives aux caractéristiques des 
variétés locales des haricots du genre Phaseolus encore cultivées ou non, les maladies et les ravageurs qui attaquent les formes végétatives des haricots, les moyens de lutte adoptés par les populations face à ces contraintes, les critères de dénomination de chaque variété locale et leurs descriptions agronomiques et culinaires (selon la perception paysanne). De même, les utilisations des haricots du genre Phaseolus par types d'espèces identifiées par Milognon et al. (2019) ont été recueillies. Afin de s'assurer des critères de dénomination évoqués par les enquêtés, sur place, une collection de ces variétés locales a été faite. En ce qui concerne les maladies et les ravageurs, deux catalogues dont l'un contenant les photos des ravageurs et l'autre celles des maladies (bactériennes, viroses et fongiques) des haricots du genre Phaseolus ont été présentés aux enquêtés pour leur identification. Après avoir identifié ou complété à nos catalogues une maladie ou un ravageur, l'enquêté propose également les moyens de lutte qu'il a l'habitude d'adopter contre ces contraintes.

Analyse statistique des données: Les données issues de cette enquête ont été analysées par statistiques descriptives (moyenne arithmétique, pourcentage ou fréquence) et les résultats ont été présentés sous forme de tableaux, de figures et graphes. Les indices de diversité et d'équitabilité de l'enquête de même que la valeur consensuelle d'usage ont été calculés afin d'évaluer la valeur accordée aux haricots en milieu paysan (Tableau 2). Le logiciel Sphinx et le tableur Excel version 2010 ont été utilisés pour l'analyse des données.

Tableau 2 : Indices ethnobotaniques calculés.

\begin{tabular}{|c|c|c|c|}
\hline Indices calculés & Méthodes & Interprétation & Références \\
\hline $\begin{array}{l}\text { Indice de diversité de } \\
\text { l'enquête (ID) } \\
\text { ID=Ux/Ut ; ID [0, n] }\end{array}$ & $\begin{array}{l}\text { ID, nombre d'utilisations citées par un } \\
\text { enquêté (Ux) divisé par le nombre } \\
\text { total d'utilisations (Ut). }\end{array}$ & $\begin{array}{l}\text { Mesure combien d'enquêtés } \\
\text { utilisent l'espèce et comment } \\
\text { cette connaissance est } \\
\text { distribuée parmi les enquêtés. }\end{array}$ & $\begin{array}{l}\text { Byg et Baslev } \\
\text { (2001). }\end{array}$ \\
\hline $\begin{array}{l}\text { Indice d'équitabilité } \\
\text { l'enquête (IE) } \\
\text { IE=ID/IDmax; IE }[0,1]\end{array}$ & $\begin{array}{l}\text { IE, valeur de la diversité divisé par la } \\
\text { valeur de l'indice de diversité le plus } \\
\text { élevé trouvé (IDmax). }\end{array}$ & $\begin{array}{l}\text { Mesure le degré d'homogénéité } \\
\text { des Connaissances des } \\
\text { enquêtés. }\end{array}$ & $\begin{array}{l}\text { Byg et Baslev } \\
(2001) \text {. }\end{array}$ \\
\hline $\begin{array}{l}\text { Valeur consensuelle } \\
\text { sur les types d'usages } \\
\text { CTU }=(\text { TU/Ut) } / \mathrm{S} \text {; } \\
\text { CTU }[-1,1]\end{array}$ & $\begin{array}{l}\text { CTU, nombre de fois que l'usage est } \\
\text { rapporté (TU) divisé par le nombre } \\
\text { total d'usages (Ut) par espèce. Cette } \\
\text { valeur est ensuite divisée par les } \\
\text { types d'usages classés par catégorie. }\end{array}$ & $\begin{array}{l}\text { Mesure le degré de } \\
\text { concordance entre les enquêtés } \\
\text { au regard des usages faits de } \\
\text { chaque espèce }\end{array}$ & $\begin{array}{l}\text { (Monteiro et al., } \\
\text { 2006). }\end{array}$ \\
\hline
\end{tabular}

\section{RÉSULTATS}

Données sociodémographiques des enquêtés et caractéristiques des haricots du genre Phaseolus au Sud et au Centre Bénin : Au total 127 individus ont été enquêtés dans la zone d'étude (Tableau 3), et, sont pour la plupart des producteurs et commerçants mais associant parfois d'autres professions telles que l'élevage, et autres (soudure, menuiserie, conduite de taxis, tradi-thérapie etc.). Parmi ces enquêtés, 88 sont des hommes (soit $69,29 \%$ ) contre 39 femmes $(30,71 \%)$ âgés de 31 à 108 ans. Ces populations enquêtées connaissent parfaitement les haricots du genre
Phaseolus et témoignent que ce sont des plantes herbacées généralement lianescentes, annuelles, parfois bisannuelles ou vivaces pour certaines d'entre elles, dans des conditions de milieu favorables. D'autres sont à croissance indéterminée, à tiges volubiles peu ramifiées qui s'enroulent autour d'un support et peuvent atteindre quatre mètres de haut ou plus selon la taille du support. II est également noté la présence de variétés à croissance déterminée et à port nain appelées en langue locale Fon «Houintakpakun». 
Tableau 3 : Taille des enquêtés par département administratif et selon le sexe.

\begin{tabular}{|l|c|c|c|}
\hline Sexe & Masculin & Féminin & Total \\
\hline Collines & & & 47 \\
Couffo & 28 & 19 & 29 \\
Zou & 21 & 8 & 51 \\
Total & 39 & 12 & 127 \\
\hline
\end{tabular}

Les haricots du genre Phaseolus étant donc bien connus des populations locales, celles-ci détiennent plusieurs connaissances sur ces espèces, notamment sur leur nomenclature vernaculaire. A cet effet, leur dénomination par les populations locales varie en fonction du groupe ethnique. Ainsi, Cinq (05) noms génériques ont été recensés à travers les quatre (04) ethnies rencontrées; les Adja les appellent
Kpahunkuin, chez les Fon/Mahi, les haricots sont appelés Akpa ou Akpakun. Dans l'ethnie Idaatcha Kpamlakun est le nom générique attribué aux haricots. Ces dénominations génériques selon les ethnies ont varié généralement suivant la couleur et la taille des graines, le type de plante et l'usage que les populations en font des différents organes de la plante (Tableau 4).

Tableau 4 : Caractéristiques des variétés locales des espèces cultivées du genre Phaseolus au Sud et au Centre Bénin.

\begin{tabular}{|c|c|c|c|c|c|}
\hline $\begin{array}{l}\text { Paramètres } \\
\text { Variété }\end{array}$ & $\begin{array}{l}\text { Couleur du } \\
\text { tégument }\end{array}$ & $\begin{array}{l}\text { Taille de } \\
\text { la graine }\end{array}$ & $\begin{array}{l}\text { Durée du } \\
\text { cycle }\end{array}$ & $\begin{array}{l}\text { Noms locaux reconnus dans les } \\
\text { milieux }\end{array}$ & Type de plante \\
\hline Locale & Rose & Petite & 3 à 4,5 mois & $\begin{array}{l}\text { Akpakun vovo ou Ajin Kpahunkuin ou } \\
\text { Akpakun vovo dogoué-dogoué }\end{array}$ & Volubile \\
\hline Locale & Blanc laiteux & Petite & 3 à 4 mois & $\begin{array}{l}\text { Akpakun wéwé bamè ou Ayou } \\
\text { Kpahunkuin }\end{array}$ & Volubile \\
\hline Locale & $\begin{array}{l}\text { Blanc tacheté de } \\
\text { noir }\end{array}$ & Petite & 3 à 4 mois & $\begin{array}{l}\text { Awadjihèfoun ou Eglin jin ou Akpakun } \\
\text { wlan-wlan ou Akpakun wlan-wlan wiwi }\end{array}$ & volubile \\
\hline Locale & $\begin{array}{l}\text { Rose tacheté de } \\
\text { rouge }\end{array}$ & Petite & 4 à 5 mois & $\begin{array}{l}\text { Akpakun wlan-wlan vovo ou } \\
\text { Kpahunkuin djo wansan-wansan ou } \\
\text { Egblin jin }\end{array}$ & Volubile \\
\hline Locale & $\begin{array}{l}\text { Blanc tacheté de } \\
\text { rouge }\end{array}$ & Petite & 3 à 4 mois & Kpahunkuin djo wansan-wansan & Volubile \\
\hline Locale & Blanc & Plus petite & 2 à 3 mois & Houintakpakun ou Doyi-Agaa & nain \\
\hline Locale & Noir tacheté de rose & Moyenne & 3 à 5 mois & $\begin{array}{l}\text { Akpakun sanwan-sanwan ou Akpakun } \\
\text { wansan-wansan ou Akpakunwiwi } \\
\text { wlan-wlan }\end{array}$ & Volubile \\
\hline Locale & $\begin{array}{l}\text { Rouge tacheté de } \\
\text { Kaki }\end{array}$ & $\begin{array}{l}\text { Moyenne à } \\
\text { grande }\end{array}$ & 5 à 6 mois & Akpakun vovo wlan-wlan & Volubile \\
\hline Locale & Brun clair & Petite & 5 à 7 mois & Koudrokou ou séssé ou Djiyikun & Volubile \\
\hline Locale & Rose tacheté de noir & Petite & 5 à 7 mois & $\begin{array}{l}\text { Koudrokou wansan-wansan ou séssé } \\
\text { wlan-wlan }\end{array}$ & Volubile \\
\hline Locale & Blanc & $\begin{array}{l}\text { Moyenne à } \\
\text { grande }\end{array}$ & 6 à 8 mois & $\begin{array}{l}\text { Nagonin Kpakun ou Akpakun wéwé } \\
\text { ou Kpamlakun founfoun ou } \\
\text { Kpahunkun yi }\end{array}$ & Semi-volubile \\
\hline Locale & $\begin{array}{l}\text { Rouge tacheté de } \\
\text { rose }\end{array}$ & Petite & 3 à 4 mois & Kpahunkuin djo wansan-wansan & Volubile \\
\hline Locale & Rouge & Grande & 5 à 7 mois & $\begin{array}{l}\text { Lègbakpakun ou Fakpakun vovo ou } \\
\text { Kpamlakun Kpikpa ou Kpahunkuin djo }\end{array}$ & volubile \\
\hline Locale & Noir & Petite & 3 à 4 mois & $\begin{array}{l}\text { Akpakun wiwi ou Kpamlakun } \\
\text { doundoun ou Kpahunkuin you }\end{array}$ & Volubile \\
\hline Locale & Rouge & Petite & 3 à 4 mois & $\begin{array}{l}\text { Kpamlakun Kpikpa ou Kpahunkuin djo } \\
\text { ou Akpakun vovo dogoué-dogoué }\end{array}$ & Volubile \\
\hline Locale & Blanc & Moyenne à & 4 à 6 mois & Akpakun wéwé cloclo ou Akpakun & Volubile \\
\hline
\end{tabular}




\begin{tabular}{|l|l|l|l|l|l|}
\hline & & Grande & & $\begin{array}{l}\text { wéwé kpabakpaba ou Kpamlakun } \\
\text { founfoun ou Gbodo Kpahunkuin ou } \\
\text { Kpahunkuin yi }\end{array}$ & \\
\hline Locale & Rose & Petite & 4 à 5 mois & $\begin{array}{l}\text { Koudrokou ou Séssévovo ou } \\
\text { Djiyikunvovo }\end{array}$ & Volubile \\
\hline Locale & Blanc laiteux & Moyenne & 4 à 5 mois & $\begin{array}{l}\text { Akpakunwéwé bamè ou Kpahunkuin } \\
\text { yi vèdomè ou Ayou Kpahunkuin }\end{array}$ & Volubile \\
\hline Locale & Blanc & Petite & 3 à 4,5 mois & $\begin{array}{l}\text { Akpakunwéwé dogoué-dogoué ou } \\
\text { Kpahunkuin yi hwè-hwè ou } \\
\text { Kpamlakun founfoun }\end{array}$ & Volubile \\
\hline
\end{tabular}

Maladies et ravageurs des haricots du genre Phaseolus et les principaux moyens de lutte des populations: Dans les champs et au niveau des produits de récolte, les producteurs et commerçants ont développé plusieurs méthodes pour diminuer les dommages des différents ravageurs et maladies des haricots du genre Phaseolus. Comme la plupart des légumineuses, les haricots du genre Phaseolus sont très vulnérables aux maladies et aux ravageurs. D'après les informations collectées auprès des enquêtés, les maladies qui attaquent les haricots peuvent être d'origine bactérienne, fongique ou des viroses alors que plusieurs espèces de bio agresseurs ont été recensées comme la cause des dommages des formes végétatives et des produits de récolte. Les symptômes de ces maladies et ravageurs sont très variables et les moyens de lutte développés par les populations locales sont à titres préventifs (Tableaux 5). La Figure 2 présente également la fréquence d'emploi des moyens de lutte adoptée par les populations contre ces maladies et ravageurs. Certains producteurs ont également témoigné que certaines espèces de ravageurs ou de vecteurs de maladies résistent à des moyens de lutte localement développés. 


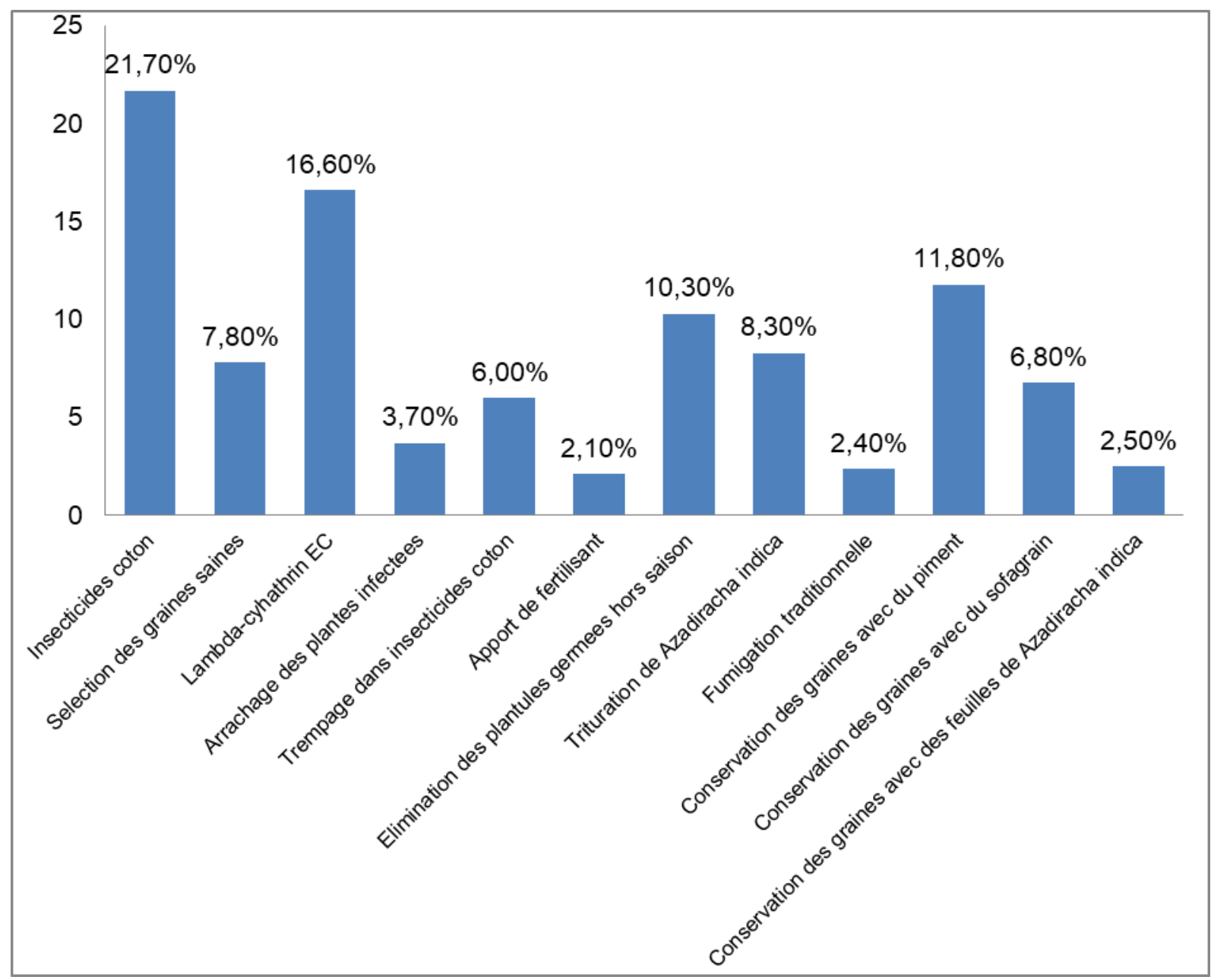

Figure 2: Moyens de lutte adoptés par les populations locales du Sud et Centre Bénin contre les maladies et ravageurs des haricots.

Tableau 5 : Diverses maladies qui attaquent les haricots du genre Phaseolus au Sud et Centre Bénin.

\begin{tabular}{|c|c|c|c|}
\hline Maladies & Symptômes & $\begin{array}{l}\text { Organes } \\
\text { attaqués }\end{array}$ & Moyens de lutte des populations locales \\
\hline $\begin{array}{l}\text { Ascochythose } \\
\text { (Ascochyta phaseolarum) }\end{array}$ & $\begin{array}{l}\text { Tâches brunâtres sur les } \\
\text { feuilles et les gousses }\end{array}$ & $\begin{array}{l}\text { Feuilles et } \\
\text { gousses }\end{array}$ & $\begin{array}{l}\text { Sélectionner les graines saines lors du semis; } \\
\text { arracher du champ les plantes infectées ; Utiliser } \\
\text { des extraits de neem (Azadiracha indica) pour } \\
\text { pulvériser les plants infectés }\end{array}$ \\
\hline $\begin{array}{l}\text { Mosaïque commune du } \\
\text { haricot (Virus BCMV) }\end{array}$ & $\begin{array}{l}\text { Plantes attaquées } r \text { sont } \\
\text { réduites; } r \text { feuilles } \\
\text { recroquevillées vers le bas ou } \\
\text { plissées }\end{array}$ & Feuilles & $\begin{array}{l}\text { Sélectionner les graines saines lors du semis; } \\
\text { Tremper des graines dans les insecticides coton } \\
\text { avant le semis; Pulvériser sur le feuillage de } \\
\text { Lambda-cyhalothrin ( } 25 \mathrm{~g} / \mathrm{L} \text { EC) ; Pulvériser sur } \\
\text { le feuillage des insecticides ducoton. }\end{array}$ \\
\hline $\begin{array}{lr}\text { Tâches farineuses } \\
\text { (Mycovellosiella phaseoli) }\end{array}$ & $\begin{array}{lr}\text { Tâches de } & \text { couleur jaune } \\
\text { diffuse qui évoluent en } \\
\text { nécroses } & \text { brunâtres } \\
\text { irrégulières, } & \text { défoliation } \\
\text { prématurée des feuilles }\end{array}$ & Feuilles & $\begin{array}{l}\text { Eliminer les plantules issues de graines germées } \\
\text { hors saison ; Sélectionner les graines saines lors } \\
\text { du semis }\end{array}$ \\
\hline $\begin{array}{l}\text { Tâches anguleuses } \\
\text { (Phaeoisariopsis } \\
\text { griseola) }\end{array}$ & $\begin{array}{l}\text { Taches anguleuses sur les } \\
\text { feuilles délimitées par des } \\
\text { nervures et tâches arrondies }\end{array}$ & $\begin{array}{l}\text { Feuilles et } \\
\text { gousses }\end{array}$ & $\begin{array}{l}\text { Pulvériser sur le feuillage de Lambda-cyhalothrin } \\
(25 \mathrm{~g} / \mathrm{L}) ; \text { Pulvériser sur le feuillage des } \\
\text { insecticides coton; arracher les plantules }\end{array}$ \\
\hline
\end{tabular}




\begin{tabular}{|c|c|c|c|}
\hline & rougeâtres sur les gousses & & infectées. \\
\hline $\begin{array}{l}\text { Anthracnose } \\
\text { (Colletotrichum } \\
\text { lindemuthianum) }\end{array}$ & $\begin{array}{l}\text { Taches arrondies, déprimées, } \\
\text { grisâtres à contours } \\
\text { rougeâtres sur les tiges, les } \\
\text { feuilles et les gousses }\end{array}$ & $\begin{array}{l}\text { Feuilles, } \\
\text { tiges et } \\
\text { gousses }\end{array}$ & $\begin{array}{l}\text { Eliminer les plantules issues de graines germées } \\
\text { hors saison; sélectionner des graines saines } \\
\text { lors des semis; Apporter de fertilisant; } \\
\text { Pulvériser sur le feuillage de Lambda-cyhalothrin } \\
(25 \mathrm{~g} / \mathrm{L})\end{array}$ \\
\hline Ravageurs & Symptômes & $\begin{array}{l}\text { Oganes } \\
\text { attaqués }\end{array}$ & Moyens de lutte \\
\hline $\begin{array}{l}\text { Bruche du haricot } \\
\text { (Acanthoscelides } \\
\text { obtectus) ou charançon } \\
\text { du haricot (Apion } \\
\text { godmani Wagner) }\end{array}$ & Perforation sur les graines & Graines & $\begin{array}{l}\text { Conserver des graines avec du piment sec, des } \\
\text { feuilles sèches de Azadiracha indica, du sofa- } \\
\text { grain, d'insecticides coton; Conserver les } \\
\text { graines par fumigation traditionnelle. }\end{array}$ \\
\hline $\begin{array}{l}\text { Mouche noir du haricot } \\
\text { (Ophiomyia phaseoli) }\end{array}$ & $\begin{array}{l}\text { Noircissement de la plante, } \\
\text { dépôt de liquide blanchâtre } \\
\text { sur les feuilles et à l'aisaile } \\
\text { des tiges. }\end{array}$ & $\begin{array}{l}\text { Feuilles, } \\
\text { tiges et } \\
\text { gousses }\end{array}$ & $\begin{array}{l}\text { Pulvériser sur le feuillage de Lambda-cyhalothrin } \\
\text { EC ( } 25 \mathrm{~g} / \mathrm{L}) \text {, Pulvériser sur le feuillage des } \\
\text { insecticides coton, pulvériser des extraits de } \\
\text { neem (Azadiracha indica) }\end{array}$ \\
\hline $\begin{array}{l}\text { Nématodes du haricot et } \\
\text { Pucerons du haricot }\end{array}$ & $\begin{array}{l}\text { Perforations des feuilles, des } \\
\text { gousses et des graines }\end{array}$ & $\begin{array}{l}\text { Feuilles, } \\
\text { gousses } \\
\text { et graines }\end{array}$ & $\begin{array}{l}\text { Pulvériser sur le feuillage de Lambda-cyhalothrin } \\
\text { EC }(25 \mathrm{~g} / \mathrm{L}) \text {; Pulvériser sur le feuillage des } \\
\text { insecticides coton, pulvériser des extraits de } \\
\text { neem (Azadiracha indica) }\end{array}$ \\
\hline $\begin{array}{l}\text { Mouche noir du haricot } \\
\text { (Ophiomyia phaseoli) }\end{array}$ & $\begin{array}{l}\text { Noircissement de la plante, } \\
\text { dépôt de liquide blanchâtre } \\
\text { sur les feuilles et à l'aisaile } \\
\text { des tiges. }\end{array}$ & $\begin{array}{l}\text { Feuilles, } \\
\text { tiges et } \\
\text { gousses }\end{array}$ & $\begin{array}{l}\text { Pulvériser sur le feuillage de Lambda- } \\
\text { cyhalothrin EC ( } 25 \mathrm{~g} / \mathrm{L}), \text { Pulvériser sur le } \\
\text { feuillage des insecticides coton, pulvériser des } \\
\text { extraits de neem (Azadiracha indica). }\end{array}$ \\
\hline
\end{tabular}

Connaissances ethnobotaniques et catégories d'usages des haricots dans la zone prospectée: Les indices de diversité et d'équitabilité de l'enquête sont respectivement $\mathrm{ID}=0,31<50 \%$ et $\mathrm{IE}=0,60$ et montrent que seulement $31 \%$ des populations de la zone d'étude utilisent les haricots et ont une parfaite connaissance sur leurs usages (IE > 50\%). Suite aux investigations dans le milieu d'étude, cinq (05) catégories d'utilisation des haricots ont été recensées : en alimentation humaine, en alimentation animale, dans le domaine cultuel/culturel, en médicine traditionnelle et dans le domaine spirituel. De ces cinq (05) types d'usages, l'alimentation humaine $(C T U=0,98)$ s'est révélée la plus importante pour les populations avec Phaseolus vulgaris, l'espèce la plus utilisée $\left(C T U_{P_{V}}=\right.$ 0,68 ) et se trouve suivie de l'usage cultuel/culturel (CTU $=0,47)$ dont les espèces Phaseolus lunatus $(0,21)$ et Phaseolus coccineus $(0,10)$ sont les plus utilisées. L'utilisation des haricots dans l'alimentation animale était la moins importante et se fait en général avec toutes les espèces cultivées du genre Phaseolus (CTU $=0,08)$ (tableau 6). 
Tableau 6 : Taux des catégories d'usages des haricots par espèce.

\begin{tabular}{c|clc|c}
\hline \multicolumn{2}{c}{ Catégories d'utilisations } & Espèces utilisées & \multicolumn{1}{c}{ CTU } & Total \\
\hline \multirow{3}{*}{ Alimentation humaine } & Phaseolus vulgaris & 0,68 & \multirow{2}{*}{0,98} \\
& Phaseolus lunatus & 0,13 & 0,98 \\
Alimentation animale & Phaseolus coccineus & 0,11 & \\
Médicinale & Autres espèces & 0,06 & \multirow{2}{*}{0,08} \\
& Toutes les espèces & 0,08 & \\
& Phaseolus vulgaris & 0,09 & \multirow{2}{*}{0,29} \\
Cultuelle/Culturelle & Phaseolus lunatus & 0,13 & \\
& Phaseolus coccineus & 0,07 & \multirow{2}{*}{0,47} \\
Spirituelle & Phaseolus vulgaris & 0,16 & \\
& Phaseolus lunatus & 0,21 & \multirow{2}{*}{0,13} \\
& Phaseolus coccineus & 0,10 & \\
\hline
\end{tabular}

\section{CTU = Valeur consensuelle d'usage.}

Connaissances culturelles/cultuelles et spirituelles liées à l'utilisation des haricots dans les groupes socio-ethniques du Sud et du Centre Bénin. : Parmi les usages culturels/cultuels cités par les populations (tableau 7), on retient que les Fons ont une bonne connaissance de l'usage des graines de haricot comme ingrédients de sacrifices des prêtres de Fâ $(47,7 \%)$ et dans les rituels aux jumeaux $(39,8 \%)$ et aux divinités Dan, Lissa et Sakpata (62,9\%). Les usages du haricot lors des sacrifices aux défunts $(53,3 \%)$ et d'enlèvement de deuil $(68,4 \%)$ sont plus connus dans l'ethnie Adja. L'usage du haricot dans la conception de la divinité Lêgba est plus connu chez les Mahi $(66,7 \%)$ mais aussi chez les Fon $(22,2 \%)$. Ainsi pour des rites de fondement de cette divinité les haricots (surtout blanc et rouge à grosses graines) constituent l'un des mets préparés (sous forme d'haricot bouilli) pour la cérémonie et les feuilles puis les graines de la variété rouge à grosses graines sont utilisées lors de l'initiation à la divinité Sakpata. En ce qui concerne les usages spirituels, au total, six (06) utilisations des haricots du genre Phaseolus ont été recensées dans la zone prospectée (Tableau 7). II s'agit de l'utilisation des vertus des feuilles pour maintenir la flamme de l'amour entre deux conjoints, pour extraire le miel, et pour augmenter le degré de chance de ceux qui y croient et pratiquent cette connaissance spirituelle. D'autres connaissances spirituelles utilisent les graines de la plante et se résument à l'utilisation mystique des graines pour accroitre le rendement d'autres cultures. Des producteurs ont rapporté que la présence des graines du haricot (Akpakun wéwé kpatchakpatcha c'est-à-dire haricot Phaseolus blanc à grosse graine) dans la poche épargnerait l'individu d'être mordu par un serpent lorsqu'il est au champ. Enfin, les racines des haricots volubiles prospectés (exception de la variété locale naine Houintakpakun) sont utilisées contre l'envoutement et la fièvre mystico-provoquée. Parmi les connaissances spirituelles recueillies, celles qui sont partagées à travers toutes les ethnies concernent le désenvoutement, l'utilisation des feuilles pour accroître spirituellement la chance et le port de graine comme une anti-morsure de serpent. 
Tableau 7 : Fréquences des usages culturels/cultuels et spirituels des haricots du genre Phaseolus suivant les groupes ethniques

\begin{tabular}{|l|l|l|l|l|}
\hline \multicolumn{1}{|c|}{ Ethnies } & Adja & Fon & Idaatcha & Mahi \\
Usages culturels/cultuels et spirituels & & & & \\
\hline Rituels aux jumeaux & $27,7 \%$ & $39,8 \%$ & $6,0 \%$ & $26,5 \%$ \\
Sacrifices aux défunts & $53,3 \%$ & $20,0 \%$ & $13,3 \%$ & $13,3 \%$ \\
Rituel aux divinités Dan et Lissa & $2,9 \%$ & $62,9 \%$ & $0,0 \%$ & $34,3 \%$ \\
Ingrédients de sacrifices des prêtres de Fâ & $15,9 \%$ & $47,7 \%$ & $10,2 \%$ & $26,1 \%$ \\
Conception de Lêgba & $0,0 \%$ & $22,2 \%$ & $11,1 \%$ & $66,7 \%$ \\
Enlèvement de deuil & $68,4 \%$ & $5,3 \%$ & $0,0 \%$ & $26,3 \%$ \\
Gris-gris de chance & $23,4 \%$ & $44,7 \%$ & $6,4 \%$ & $25,5 \%$ \\
Désenvoutement & $28,2 \%$ & $38,0 \%$ & $8,5 \%$ & $25,4 \%$ \\
Extraire le miel & $0,0 \%$ & $100 \%$ & $0,0 \%$ & $0,0 \%$ \\
Anti-serpent & $3,7 \%$ & $55,6 \%$ & $7,4 \%$ & $33,3 \%$ \\
Améliorer le rendement d'autres cultures & $12,5 \%$ & $0,0 \%$ & $0,0 \%$ & $87,5 \%$ \\
Stimuler l'amour conjugal & $52,0 \%$ & $36,0 \%$ & $0,0 \%$ & $12,0 \%$ \\
\hline
\end{tabular}

\section{Connaissances médicinales liées à l'utilisation des} haricots dans la zone d'étude : Au Sud et Centre du Bénin, les populations détiennent plusieurs connaissances médicinales sur les haricots. Onze (11) recettes impliquant les haricots pour le traitement de diverses affections ont été recensées (Figure 3). Ainsi, les graines des haricots sont utilisées pour favoriser la suppuration d'abcès ou d'inflammations corporelles (18,5\% et $12,5 \%$ respectivement des enquêtés) et les feuilles sont utilisées dans le traitement de la teigne $(16,7 \%)$. De même, les feuilles et les graines des haricots entrent respectivement dans les traitements traditionnels des morsures de serpent $(2,4 \%)$ et de la toux $(1,8 \%)$. Une autre connaissance des haricots en médicine traditionnelle utilise les feuilles de ces plantes dans le traitement des maux d'oreille $(5,2 \%)$. Par ailleurs, les feuilles triturées de haricots sont adoptées pour arrêter l'hémorragie en cas de plaie vive (21\%) ou pour affaiblir les effets d'enflement en cas de piqures d'abeille $(12,8 \%)$, de guêpe( $2,7 \%)$, ou de scorpion $(4,6 \%)$. Aussi, la consommation du haricot bouilli a été révélée comme une alternative contre la faiblesse sexuelle $(1,5 \%)$.

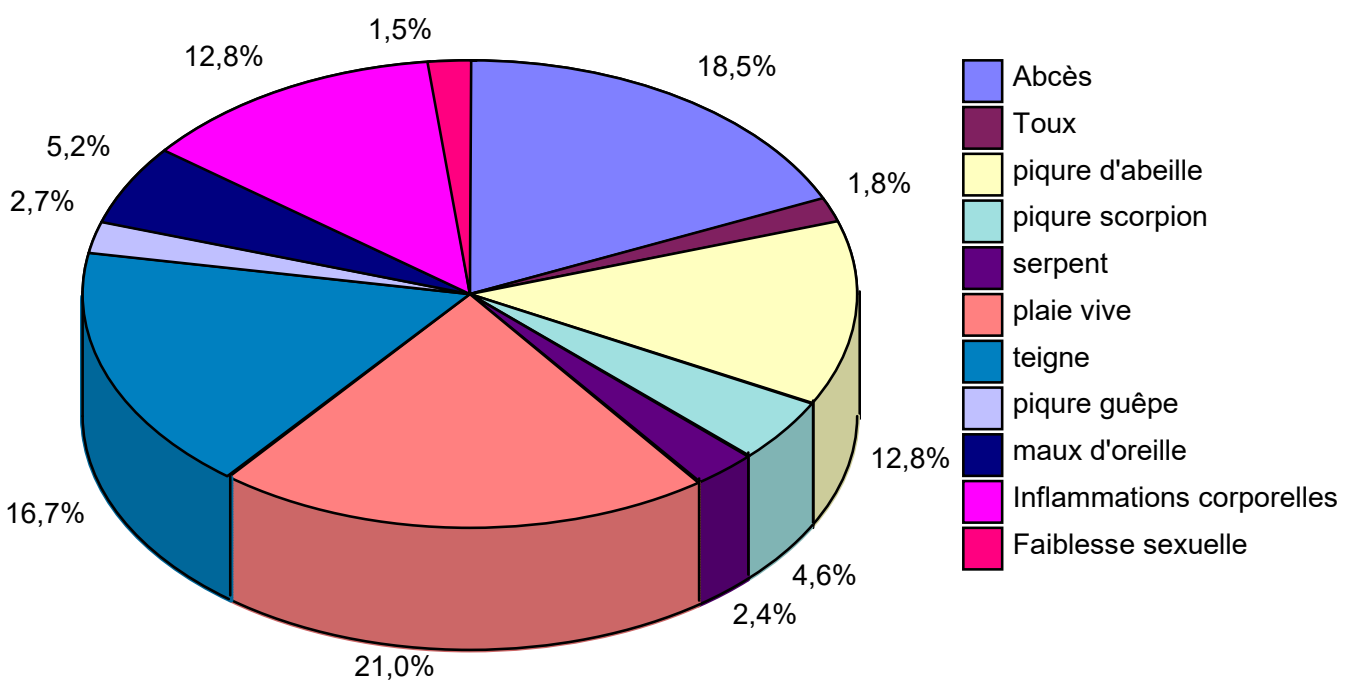

Figure 3 : Usages en médecine traditionnelle des haricots dans la zone prospectée. 
Mode de préparation des mets à base des haricots : Les haricots du genre Phaseolus sont utilisés dans la préparation de trois (03) principaux mets dont la fréquence d'emploi est présentée sur la Figure 4. Ils peuvent être préparés comme haricots bouillis accompagnés de la farine de manioc (gari) et de l'huile. Ce met est appelé localement Abobo en Fon/Mahi, Tchotcho en Idaatcha (Figure 5). Les Adja reconnaissent ce met mais ne lui attribue pas un nom particulier. Au lieu de le faire accompagner avec la farine du manioc, d'autres consommateurs préfèrent la farine de maïs qu'ils font griller (à l'aide d'un récipient clos ou d'une marmite) ou non. Ce met localement appelé Yonmilin ou Djohoungoli (Fon/Mahi) est souvent accompagné de l'huile de noix du palme (huile rouge) ou l'huile d'arachide tout comme le haricot bouilli. La troisième forme de préparation est son association avec le riz appelée Attassi. Ce met est souvent accompagné de la sauce de tomate ou rarement d'arachide. Cette dernière pratique est plus fréquente dans les ethnies Idaatcha et Mahi. Des rares ménages s'adonnent à la préparation de Toutou ou Bokoun qui consiste à associer les haricots du genre Phaseolus avec le maïs grain.

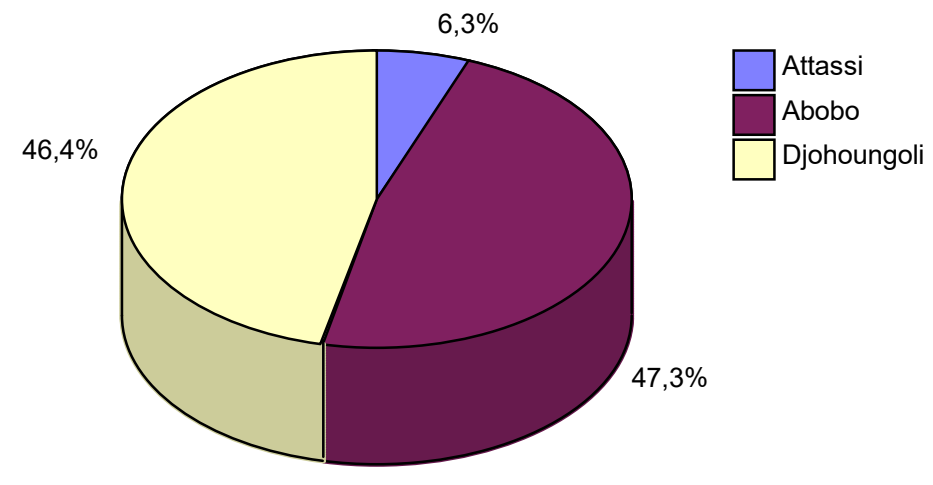

Figure 4 : Fréquence de citation des principaux mets à base des haricots du genre Phaseolus.

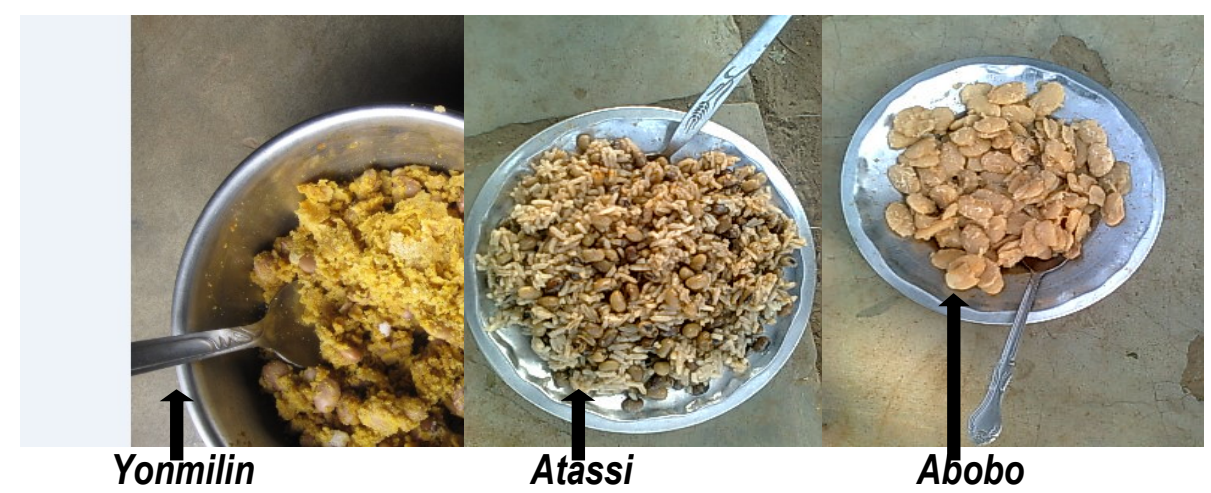

Figure 5 : Photos montrant les principaux mets à base des haricots.

\section{DISCUSSION}

$\mathrm{Au}$ Sud et au Centre Bénin, les haricots du genre Phaseolus constituent pour les communautés locales, des cultures traditionnelles qui tiennent une place importante dans l'alimentation humaine surtout pour les ménages contractant des naissances rapprochées ou ayant des ressources alimentaires limitées. Ceci trouve son fondement dans les résultats d'études d'organisme international (FAO, 2016) et des scientifiques d'horizons divers (Nyabyenda, 2005 ; Nzungize, 2012 ; Nicolai et al., 2015) qui soutiennent que les haricots sont riches en glucides complexes et fibres qui se digèrent lentement en apportant une sensation de satiété. En effet, les raisons majeures qui motivent la culture des haricots à l'échelle villages concernent entre autre l'autoconsommation, le goût aromatisé des haricots, le gonflement à la cuisson et la production à moindre coût avec un bon rendement. Aussi, selon les producteurs du Sud et du Centre Bénin, les haricots du genre Phaseolus sont des cultures qui améliorent la qualité des sols à travers leurs feuilles mortes enfouies 
dans les sols. Ainsi, dans les villages, les petits fermiers constituent la cible privilégiée qui s'adonne à cette culture car ne disposant pas d'assez de terre cultivable fertile ni de moyens adéquats pour assurer les coûts de productions en matières de fertilisants. Par conséquent, la gestion durable de ces cultures pallierait un tant soit peu aux peines des producteurs démunis. La plupart des études scientifiques menées sur les haricots ont révélé leur richesse en protéines (20 à $30 \%$ ) puis en oligoéléments (Baudouin et al., 2001 ; Pujolà et al., 2007 ; Ismet et al., 2011 ; Roméro et al., 2013) de même que leur contribution à l'amélioration des systèmes agraires (N'gbesso et al., 2013; Scheider et al., 2015). En plus de ces considérations nutritionnelles et agronomiques mentionnées dans diverses études scientifiques et reconnues aussi des populations locales du Bénin, les résultats de la présente étude élargissent le champ d'utilité des haricots du genre Phaseolus vers des connaissances culturelles/cultuelles, médicinales et spirituelles dont certaines d'entre elles ont été recensées par Loko et al. (2018) avec des différences d'utilisation pour une même fin. Aussi faudrait-il souligner que Loko et al. (2018) ont inventorié leurs connaissances sur l'espèce Phaseolus vulgaris. Or selon les études de Milognon et al., 2019 sur le genre Phaseolus et la description paysanne des variétés locales issue de cette étude de même que nos résultats de la caractérisation agromorphologique dans ce genre (in press), la plupart des variétés locales utilisées par les populations locales dans les domaines culturel/cultuel, médicinal et spirituel ne sont pas de l'espèce Phaseolus vulgaris mais plutôt des espèces Phaseolus lunatus et Phaseolus coccineus. C'est le cas par exemple de séssé, de mitonyikun et bien d'autres variétés locales recensées à tort par Loko et al., 2018 comme appartemenant à l'espèce Phaseolus vulgaris. Ainsi, la clarification des espèces du genre Phaseolus reste une étape sans laquelle les axes de recherches sur cette spéculation ne seraient abordés sans biais par les auteurs au Bénin. De ce qui précède, la pérennité de la culture des haricots surtout des espèces utiles dans la tradition, assurerait en partie la conservation et la pérennité des patrimoines culturels et cultuels de nos peuples.

Les faibles proportions (par rapport aux autres connaissances médicinales) de certaines connaissances médicinales (toux, serpent, piqure de guêpe et faiblesse sexuelle) recensées lors de cette étude montrent qu'elles ne sont pas partagées dans toutes les ethnies et cette observation pourrait être due d'une part à la méconnaissance de la plante et de ces vertus par la jeune génération et d'autre part au fait que ces populations font recours aux méthodes modernes de traitement ou à d'autres plantes médicinales pour satisfaire les mêmes besoins. De plus, la variété locale (rouge à grosses graines) utilisée dans le traitement de la toux chez les enfants n'est plus cultivée par les producteurs de toutes les ethnies rencontrées car elle présente un goût très amer à la cuisson et a un cycle plus long et sa consommation est réservée uniquement à la divinité Lêgba. Sa collecte a été faite fortuitement dans le marché de Glazoué (département des Collines). Certaines des connaissances médicinales (maux d'oreille, inflammations corporelles, etc.) citées par les populations du Sud et Centre Bénin ont été déjà rapportées dans des travaux scientifiques avec quelques différences d'utilisations contre les mêmes maux. En effet, Wortmann rapportait en 2006 qu'au Sénégal et en République Démocratique du Congo, le jus des feuilles des haricots sert à préparer des instillations nasales contre les maux de tête et les gouttes contre les otites; de même pour favoriser la suppuration des tumeurs ou d'abcès, les graines de haricot écrasées ou réduites en poudre frottées dans de petites coupures sont fortement utilisées par les populations locales nigérianes. Malgré ces importances qui font des haricots une culture de choix pour les populations locales, de sévères contraintes biotiques recensées déjà par des auteurs (Nonveiller, 1984 ; Mukeshimana et al., 2005 ; Hillocks et al., 2006 ; Miklas et al., 2006 et Ndomo et al., 2009) ruinent cette spéculation dans les champs de même que les produits issus de sa récolte dont, les producteurs et commerçants béninois développent à leur manière des moyens plus ou moins conséquents de lutte. Parmi les divers moyens de lutte recensés dans cette étude, l'utilisation des insecticides du coton pour maîtriser les ravageurs, les viroses des plantes et les maladies bactériennes et fongiques est la plus fréquente $(21,7 \%)$. Ceci se justifie par le fait que des insecticides spécifiques aux haricots ne seraient pas disponibles sur le marché et selon les producteurs, la plupart des maladies virales, fongiques et bactériennes des haricots sont aussi celles qui menacent le cotonnier. D'où, les producteurs appliquent les insecticides du coton aux haricots pour réduire les pertes de rendement occasionnées par ces maladies et ravageurs. Cependant, certains moyens de lutte traditionnels et très anciens comme la fumigation traditionnelle, le traitement par pulvérisation des feuilles fraîches triturées de neem (Azadiracha indica) et la 
conservation des graines avec du piment ou les feuilles sèches de neem (Azadiracha indica) continuent d'être appliqués par d'autres producteurs. Cette préférence de traitement ou de conservation de haricot avec Azadiracha indica ou avec du piment $(8,30 \% ; 2,5 \%$ et $11,80 \%$ respectivement (Figure 2 ) se justifierait par le fait que ces méthodes de traitement ou de conservation sont pratiquement sans conséquences négatives sur la santé des consommateurs de ces produits par rapport aux méthodes de traitement ou de conservation avec des produits chimiques tels que les sofagrins les insecticides coton ou de Lambda-cyhalothrin $(25 \mathrm{~g} / \mathrm{L})$. A cette raison, peut s'ajouter le coût élevé de ces intrants obligeant les petits fermiers à ressources financières limitées de préférer ces moyens traditionnels de lutte. Les valeurs de l'indice de diversité totale et d'équitabilité totale en relation avec les utilisations sont relativement élevées $(0,31$ et 0,60 respectivement) en comparaison de celles obtenues par Déguénonvo, 2011 sur Mondia whitei et Akouèhou et al., 2014 sur le Arthocarpus altilis. Ces résultats s'expliqueraient par le fait que les connaissances traditionnelles sur les haricots sont presque équitablement réparties à travers les diverses ethnies rencontrées au cours de la prospection avec une transmission homogène des connaissances de génération en génération. Aussi, Akouèhou et al., 2014 n'ont-ils pas signalé que Arthocarpus altilis est une espèce retrouvée à dominance dans les bas-fonds et les zones marécageuses (ayant une écologie bien définie). Par conséquent, les connaissances et les utilisations sont plus restreintes aux peuples ou groupes ethniques de sa zone de prédilection sans une bonne diffusion par

\section{CONCLUSION}

Cette étude, qui avait pour but de recenser les traits locaux de dénomination, les maladies et ravageurs qui et d'analyser la valeur accordée aux haricots du genre Phaseolus cultivés dans le Sud et Centre du Bénin a montré qu'il existe une hétérogénéité des noms donnés par les agriculteurs à leurs variétés et le soupçon de synonymes et d'homonymes entre les différentes populations, mais aussi une diversité élevée entre les accessions traditionnelles, exprimée par les différents traits des graines (couleur des graines, taille ou aspect des graines). L'analyse de l'importance socio-culturelle a montré que les haricots du genre Phaseolus sont d'une grande importance tant aux plans alimentaire, médicinal, cultuel/culturel que spirituel pour les populations locales. Mais malheureusement leur culture rapport aux haricots qui sont des cultures flexibles connues de bon nombre de peuples. Les proportions de la pratique culturale qui consiste à associer les haricots avec l'igname (Dioscorea spp.), le sorgho (Sorghum bicolor) et le pois d'angole (Canjanus canjan) sont faibles et ceci pourrait être dû à la présence de ces cultures dans seulement une partie (collines) de la zone d'étude. Ainsi, les tiges du sorgho, les pieds de pois d'angole de la dernière campagne ou même de la campagne en cours de même que les tuteurs de l'igname servent en même temps de tuteurs pour le haricot. Sa culture dans des jardins de case ou près des maisons est plus connue chez les Fon et se justifie par les connaissances spirituelles que ces populations détiennent sur la plante. En effet, la présence de cette plante dans une concession constitue une barrière contre les mauvais esprits, le serpent ou les abeilles missionnaires (commandités par envoutement) car selon les producteurs, les feuilles et les fleurs des haricots détiennent des substances qui repoussent les abeilles; ce qui justifie l'utilisation des vertus de leurs feuilles dans l'extraction du miel. Aussi, elle procurait également de chance pour les ménages qui la pratiquent près des maisons. Par ailleurs le faible taux d'association (moins de 10\%) des haricots avec le palmier à huile se traduirait par la forte régression que connait le palmier à huile ces dernières années. Du fait que la lumière solaire traverse les folioles du palmier, il est d'après les producteurs l'arbre vert par excellence pouvant servir de tuteur pour les haricots à l'état juvénile. Une relance de cette filière contribuerait donc à lever la contrainte majeure du haricot qu'est le manque de tuteurs.

connaît une forte régression au point où certains cultivars sont menacés de disparition due principalement aux contraintes biotiques. Ces contraintes persistent en raison de non disponibilité de moyens de lutte efficace et de variétés améliorées performantes pouvant les surmonter. Dans le but d'avoir une vue globale sur les haricots du genre Phaseolus au Bénin, il est vivement souhaité d'étendre cette étude à l'échelle nationale afin de recenser les types d'usages d'autres ethnies et de disposer d'un plus grand nombre d'accessions. Ceci facilitera la mise en place d'un programme conséquent d'amélioration variétale et d'une bonne stratégie de conservation des ressources génétiques des haricots. 


\section{REMERCIEMENTS}

Les auteurs remercient sincèrement les Professeurs Corneille AHANHANZO, Jeanne ZOUNDJIEKPON et Hubert ADOUKONOU-SAGBADJA du Département de Génétique et des Biotechnologies de l'Université d'Abomey-Calavi pour leurs divers conseils au cours de

\section{RÉFÉRENCES BIBLIOGRAPHIQUES.}

Adoukonou-Sagbadja $H$, Dansi $A$, Vodouhè $R$, Akpagana K. 2006. Indigenous knowledge and traditional conservation of fonio millet (Digitaria exilis, Digitaria iburua) in Togo. Biodiversity \& Conservation 15(8): 2379-2395.

Akoègninou $A$, van der Burg WJ, van der Maesen LJG. 2006. Flore Analytique du Bénin, Backhuys Publishers, Leiden, the Netherlands.

Akouehou GS, Goussanou CA, Idohou R, Dissou FE. Azokpota P, 2014. Importance socioculturelle de Artocarpus altilis (Parkinson) Fosberg (Moraceae) au Sud-Bénin. Journal of Applied Biosciences 75: 6173- 6182.

Aly D, Dah-Dovonon Z J, Dansi A. 2007. Deuxième rapport sur l'état des ressources phytogénétiques pour l'alimentation et l'agriculture au Bénin. Ministère de l'Agriculture de l'Elevage et de la Pêche, 59p.

Baudoin JP, Demol J, Louant BP., Maréchal R, Mergeai G, Otoul E. 2002. Amélioration des plantes : application aux principales espèces cultivées en régions tropicales. Gembloux: Presses Agronomiques de Gembloux

Baudoin JP. 2001. Contribution des ressources phytogénétiques à la sélection variétale de légumineuses alimentaires tropicales. Biotechnologie, agronomie, société et environnement 5(4) : 221-230

Bayuelo-Jiménez JS, Debouck DG, Lynch JP. 2003. Growth, gas exchange, water relations, and ion composition of Phaseolus species grown under saline conditions. Field Crop Resistance 80 (3): 207-222.

Broughton WJ, Hernandez G, Blair MW, Beebe S, Gepts P, Vanderleyden J. 2003. Beans (Phaseolus spp.) - Model Food Legumes. Plant and Soil 252: 55-128.

Byg A et Balslev H. 2001. Diversity and use of palms in Zahamena, eastern Madagascar. Biodiversity and Conservation 10(6): 951-970.

Caixeta ET, Borém A, Azevedo Fagundes S, Niestche S, Barros EG, Moreira MA. 2003. Inheritance of angular leaf spot resistance in common la rédaction du manuscrit; $M$. Jonas $B O C O$ et le $\mathrm{Dr}$. Rolande A. DAGBA pour leurs diverses contributions. Nos remerciements vont également aux autorités locales et aux producteurs qui ont accepté volontiers partager leurs connaissances avec nous.

bean line BAT 332 and identification of RAPD marker linked to the resistance gene. Euphytica 134: 297-303.

CIAT. 1989. Constraints and opportunities for improving bean production. A planning document 199398. An achievement document 1987-92, CIAT (Centro Internacional de Agricultura Tropical), Cali, Colombia.

Dagnelie P. 1998. Statistique théorique et appliquée: Tome 2, Inférence statistique à une et à deux dimensions. De Boek \& Larcier, Paris, Bruxelles 2.

Deguenonvo MN. 2011. Evaluation écologique et socioéconomique de Mondia whitei (hook.f.) Skeels (asclepiadaceae) au Sud-benin. Thèse d'ingénieur agronome, FSA/UAC, $64 p$.

FAO. 2016. Les bienfaits pour la santé des légumineuses, fao.org/pulses-2016,4p.

Freytag GF, Debouk DG. 2002. Taxonomy, distribution, and ecology of the genus Phaseolus (Leguminosae-Papilionodeae) in North America, Mexico and Central America. Sida, Botanical Miscellany 23. Botanical Research Institute of Texas.

Gbaguidi AA, Adjatin A, Dansi A, Agbangla C. 2015. Diversity of cowpea (Vigna unguiculata (I.) Walp.) Landraces in Central and Northern Benin. International Journal of Current Microbiology and Applied Sciences 4(11): 487504.

Hillocks RJ, Madata CS, Chirwa R, Minja EM, Msolla S. 2006. Phaseolus bean improvement in Tanzania, 1959-2005. Euphytica 150: 215 231.

Ismet B et Firkret Y. 2011. Characterization of Bean (Phaseolus vulgaris L.) cultivars grown in Turkey by SDS-PAGE of seed proteins. Pakistan Journal Botany 43(2) :1085-1090.

IRAD. 2013. Contribution de la recherche à l'amélioration de la production et la consommation des légumineuses alimentaires au Cameroun, C2D/ Programme d'Appui à la 
Recherche Agronomique, Projet 6: Légumineuses, 57p.

Loko LEY, Toffa J, Adjatin A, Akpo AJ, Orobiyi A, Dansi A. 2018. Folk taxonomy and traditional uses of common bean (Phaseolus vulgaris L.) landraces by the sociolinguistic groups in the central region of the Republic of Benin. Journal of Ethnobiology and Ethnomedicine 14(52): 1 15.

Mahuku GS, Jara CE, Cajiao C, Beebe S. 2002. Sources of resistance to Colletotrichum lindemuthianum in the secondary gene pool of Phaseolus vulgaris and in crosses of primary and secondary gene pools. Plant Disease 86:1383-1387.

Marilyn LB, Jay KU. 2011. A proprietary alpha-amylase inhibitor from white bean (Phaseolus vulgaris): A review of clinical studies on weight loss and glycemic control. Nutrition Journal 10(24): 110.

Miklas PN, Kelly JD, Beebe SE, Blair MW. 2006. Common bean breeding for resistance against biotic and abiotic stresses: From classical to MAS breeding. Euphytica 147: 105-131.

Milognon HW, Missihoun AA, Sedah P, Agbo RI, Assogbadjo AE, Agbangla C. 2019. Utilisation des microsatellites chloroplastiques (SSRcp) dans la relation phylogénétique des haricots cultivés du genre Phaseolus au Centre et Sud Bénin, Afrique de l'Ouest. Afrique SCIENCE 15(1) :1-11.

Missihoun AA, Agbangla C, Adoukonou-Sagbadja H, Ahanhanzo C, Vodouhê R. 2012. Gestion traditionnelle et statut des ressources génétiques du sorgho (Sorghum bicolor $\mathrm{L}$. Moench) au Nord-Ouest du Bénin. International Journal of Biological and Chemical Sciences 6(3):1003-1018.

Missihoun AA, Milognon HW, Montcho D, Agbo RI, Sedah P, Agbangla C. 2017. Diversité variétale et gestion paysanne des haricots cultivés du genre Phaseolus cultivés au Centre et Sud Bénin (Afrique de l'Ouest). Journal of Applied Biosciences 118: 11817-11828.

Monteiro JM, Albuquerque UP, Lins Neto EMF., Araújo EL, Amorim ELC. 2006. Use Patterns and Knowledge of Medicinal Species among Two Rural Communities in Brazil's Semi-Arid Northeastern Region. Journal of Ethnopharmacology 105: 173- 186.
Mukeshimana G, Paneda A, Rodriguez C, Ferreira JJ, Giraldez R, Kelly JD. 2005. Markers linked to the bc-3 gene conditioning resistance to bean common mosaic potyviruses in common bean. Euphytica 144: 291-299.

N'gbesso MF-P, Fondio L, Dibi BEK, Djidji HA, Kouame CN. 2013. Étude des composantes du rendement de six variétés améliorées de niébé (Vigna unguiculata L.). Journal of Applied Biosciences 63: 4754-4762.

Ndomo AF, Tapondjou AL, Tendonkeng F, Tchouanguep FM. 2009. Evaluation des propriétés insecticides des feuilles de Callistemon viminalis (Myrtaceae) contre les adultes d'Acanthoscelides obtectus (Say) (Coleoptera; Bruchidae). Tropicultura 27 (3): 137-143.

Nicolai P, Erick B, James P W, Richard F H. 2015. Review: The Potential of the Common Bean (Phaseolus vulgaris) as a Vehicle for Iron Biofortification. Nutrients $7: 1144-1173$.

Nonveiller G. 1984, Catalogue commenté et illustré des insectes du Cameroun d'intérêt agricole (apparition, répartition, importance).Beograde, Vojvodebrane, $210 p$.

Nyabyenda P. 2005. Les plantes cultivées en régions tropicales d'altitude d'Afrique : Généralités, Légumineuses alimentaires, Plantes à tubercules et racines, Céréales. Presses agronomiques de Gembloux, Bruxelles, 225p.

Nzungize RJ. 2012. Identification of Pythium species inducing common bean (Phaseolus vulgaris L.) root rot symptoms and development of backcrosses to improve the level of varietal resistance to this disease, these de Doctorat, Sciences Agronomiques et Ingénierie, 198p.

Pujolà M, Farreras A, Casanas F. 2007. Protein and starch content of raw, soaked and cooked beans (Phaseolus vulgaris L.). Food Chemistry 102: 1034-1041.

Romero AO, Damian HMA, Rivera TJA, Baez SA, Huerta LM, Cabrera HE. 2013. The Nutritional value of Beans (Phaseolus vulgaris L.) and its importance for Feeding of Rural communities in Puebla-Mexico. International Research Journal of Biological Sciences 2(8): 59-65.

Scheider A, Huyghe C, Maleplade T, Labalette F, Peyronnet C, Carrouée E. 2015. Rôle deslégumineuses dans l'agriculture française. In : Schneider A. \& Huyghe $C$. (Coordonnateurs), Les légumineuses pour des 
systèmes agricoles et alimentaires durables, Quae, Versailles, France, 11-77pp.

Taylor C, Buckley J, Champ M, Patterson CA. 2012. The nutritional value and health benefits of pulses for obesity, diabetes, heart disease and cancer. British Journal Nutrition 108: 1-165.

Wortmann CS. 2006. Phaseolus vulgaris L. - haricot sec. In: Brink, M, \& Belay, G, (Editeurs), PROTA 1: Cereals and pulses/Céréales et légumes secs. PROTA, Wageningen, Pays Bas. Consulté le 31 mai 2016 